\title{
Hurdles in US Surgical Training for International Medical Graduates
}

\author{
Vijay K. Mittal ${ }^{1}$ - Elizabeth A. Lax ${ }^{1}$
}

Published online: 1 July 2016

(C) Association of Surgeons of India 2016

Non-US citizen foreign graduates make great sacrifices to obtain a residency position in the USA. They must overcome financial, social, and geographical challenges when moving to America. Obstacles such as ECFMG certification, United States Medical Licensing Examination (USMLE) testing, application fees, interview travel costs, and obtaining a visa all add up to a great financial burden which can be approximately $\$ 25,000$ for some international medical graduates (IMGs) [1]. The decision to undertake this path is a difficult one to make, and is compounded by a lack of data demonstrating that completion of a preliminary year in surgery directly benefits the applicant. It would be beneficial for these candidates to have a realistic idea of the likelihood they have matching into a categorical position in the future.

The overall match rate for all specialties for non-US citizen IMGs in 2015 was $49.5 \%$ [2]. The competition experienced by IMGs when applying for a 5-year categorical position in general surgery is overwhelming. Applicants are often left unmatched, and applying for a 1-year preliminary surgery position is an attractive option as a way to gain experience and strengthen applications for a categorical position the following year. However, completion of a preliminary surgery year does not always guarantee the candidate a categorical position in the future and accepting this position can be risky.

The preliminary position is essential to training programs in order to balance work-hour restrictions and personnel requirements. In return, these positions can be valuable in that they provide experience and a path toward a career in surgery.

Elizabeth A. Lax

Vijay.Mittal@providence-stjohnhealth.org

1 Department of Surgery, Providence Hospital and Medical Centers, Southfield, MI, USA
However, the position has been referred to as a "dead end" for those looking to continue on in general surgery [3].

Although there are a number of residents who are IMGs, the number of US medical graduates accepted to categorical positions far exceeds the IMG. In the 2015 match, 121 out of 1085 IMG applicants matched categorical surgery. There were a total of 1219 categorical positions filled, of which 1101 (90\%) were filled by American graduates and 121 (10\%) by IMGs, both US citizen $(n=71,5 \%)$ and non-US citizen $(n=50,4 \%)$. The majority of IMGs matching to categorical positions completed a preliminary year [2].

The small number of IMGs matching into general surgery (GS)-categorical positions can possibly be explained by the program director's perceptions of these candidates. Moore and Rhodenbaugh published a study showing that a majority of GS residency program directors believe that IMGs are subject to discrimination during the candidate selection process [4]. They also reported that $20 \%$ of the PDs that responded to their survey felt pressure to rank less qualified American graduates above IMGs who were more qualified.

Several other factors for IMG applicants to overcome include obtaining high scores on the USMLE Step 1 and 2 and making an exceptional impression on interview day [5].

Makdia et al. published a recent study examining the criteria used to select candidates for residency positions in GS [6]. They reported that the number one most important factor in the screening process is USMLE Step 1 scores, followed by USMLE Step 2 scores, as well as if the applicant was a graduate from a Liaison Committee on Medical Education (LCME)-accredited medical school. The LCME accredits schools located in the USA and Canada and does not accredit foreign medical schools. This study also noted that the most important factor for ranking a candidate was the interview. While this study does not reflect the criteria of all training programs in the 
USA, it does shed light on the criteria that IMGs must fulfill in order to be considered for a position [4-6].

Several reports exist examining the outcome of preliminary residents; however, none focus specifically on the fate of IMGs. At our institution, we reviewed the outcomes of preliminary residents from 1990 through 2015. A total of 103 residents completed a year as a non-designated preliminary surgery resident from 1990 to 2015 . Ninety-six of these residents were IMGs $(93 \%)$ ). After completing their year of preliminary training in surgery, four IMGs returned to their home countries; therefore, they were excluded from the study. A total of 92 IMGs were ultimately included in this study. Seventy graduates $(70 / 92,76 \%)$ matched into general surgery categorical or other surgical-related specialties (i.e., OB-GYN, anesthesia, orthopedics, plastic surgery). Forty-four residents $(44 / 92,45 \%)$ matched into general surgery categorical positions, and 33 of those residents (33/44, $75 \%)$ obtained categorical positions at our own institution. Twenty-two graduates (22/92, $23 \%$ ) pursued non-surgical-related careers (i.e., internal and family medicine, radiology, pathology).

For those preliminary graduates who matched into categorical surgery, the overall experience of a preliminary year was beneficial for their career. However, there still exists a risk when accepting a preliminary position because there is no guarantee that completing a preliminary year will automatically advance a resident to a categorical position. Even without a guarantee for advancement to a categorical position, it is somewhat unjustified to describe the preliminary position as a "dead end." The majority of preliminary graduates that did not match into categorical positions were able to ultimately attain competitive positions in other fields. While there is a risk that a graduate may not match into general surgery, it certainly is evident that the 1-year experience is helpful for attaining a job within the US medical system.

It is important to note that the majority of US citizen IMGs from our program have graduated from "offshore medical schools" which are for-profit institutions primarily located in the Caribbean region. An advantage that these candidates have when applying for categorical positions is that their training during the clinical phase of medical school is conducted within the USA. This allows the candidate to acclimate to the American medical system, develop contacts within US residency programs, and find mentors within the surgical field.

International medical graduates need to be aware of the extremely competitive nature of general surgical residency. A preliminary position may allow them to adapt to the US system, but may not guarantee that the resident will be able to continue with a career in general surgery. It may benefit US residency programs to take into cognizance the obstacles faced by IMGs and possibly re-evaluate the purpose that the preliminary position serves within their residency program. With the looming prediction of a future shortage in the number of general surgeons practicing within the USA, it might be time that an open discussion takes place on the true purpose of the preliminary residency position and if it aids in helping programs fill categorical positions with the most qualified and capable candidates. General surgery will continue to remain a very competitive field, and it is important that non-US citizen applicants utilize the opportunity to adapt themselves to the US system and keep an open mind toward other surgical specialties.

\section{References}

1. Leon LR Jr, Ojeda H, Mills JI Sr et al (2008) The journey of a foreign-trained physician to a United States residency: controversies surrounding the impact of this migration to the United States. J Am Coll Surg 206:171-176

2. National Resident Matching Program (2015) Results and data: 2015 main residency match. National Resident Matching Program, Washington, DC

3. Christein JD, Cook JK, Enger TM, Farley DR (2006) Preliminary general surgery residents: indentured servitude or golden opportunity? Curr Surg 63:85-89

4. Moore RA, Rhodenbaugh EJ (2002) The unkindest cut of all: are international medical school graduates subjected to discrimination by general surgery residency programs? Curr Surg 59:228-236

5. Go PH, Klaassen Z, Chamberlain RS (2012) An ERAS-based survey evaluating demographics, United States Medical Licensing Examination performance, and research experience between American medical graduates and United States citizen international medical graduates: is the bar higher on the continent? J Surg Educ 69:143-148

6. Makdisi G, Takeuchi T, Rodriguez J et al (2011) How we select our residents - a survey of selection criteria in general surgery residents. J Surg Educ 68:67-72 